\title{
An Interpretation Based on the Theory of Iconology for the Pottery Head Sculpture with Patterns Carved on the Forehead and Cheeks Unearthed at Shuangdun Culture Ruins in Anhui Province, China
}

\author{
Xinyu Dai, Hao Xu \\ School of Art, Anhui University of Finance and Economics, \\ 962 Caoshan Road, Bengbu City, Anhui Province, China
}

\begin{abstract}
In the Neolithic Age, the Huaihe River basin was located at the region where the north and south cultures converged and intersected, and the Shuangdun cultural ruins in Shuangdun village, Huaishang district, Bengbu city, in the north shore of the Huaihe River, is the most ancient Neolithic cultural ruins discovered in the middle region of the Huaihe River basin with a history of 7300-6600 years approximately. The pottery head sculpture with patterns carved on the forehead and cheeks, unearthed at the ruins, as a national first-grade cultural relic, is the most ancient physical proof of carved facial patterns discovered in China so far. From the perspective of art history, analyzed with Iconology, the paper dedicates to interpreting the theme conveyed in the visual art of the pottery sculpture and the deep implicit meaning and establishing the connection between the physical proof and the historical background. Based on the exploration of the pottery head sculpture with patterns carved on the forehead and cheeks, it is interpreted as a feature of the Shuangdun culture that originated in the Huaihe River culture system.
\end{abstract}

Keywords: Shuangdun culture, Pottery head sculpture with patterns carved on the forehead and cheeks, Iconology, The Huaihe River culture system.

\section{Introduction}

In the Neolithic Age, the Huaihe River basin was located in the region where the north and south cultures converged and intersected. Su Bingqi, the renowned archaeologist, proposed the inference that neither the Yellow River basin nor the Yangtze River basin can be expanded to the Huaihe River basin conceptually or geographically, and in all probability, there is one or multiple important ancient civilizations in this region [1]. And he expounded on the significance of respective discussions on the Huaihe River culture system and those from the cultures of the Yellow River Basin and the Yangtze River Basin.

The Shuangdun culture ruins in Shuangdun village, Huaishang district, Bengbu city, in the north shore of the Huaihe River, is the most ancient Neolithic cultural ruins discovered in the middle region of the Huaihe River basin with a history of 7300-6600 years approximately. According to the Chronicle of Aigong of Kingdom Lu, B.C.488- 483 in Tradition of Zuo, the southwest of the ruins was the locality where $\mathrm{Yu}$ the Great convened thousands of kings holding jades and silk cloth to establish the Xia Dynasty. It was called the Mt. Tushan Alliance in history, thus, making the historical position of that region ever prominent.

The pottery head sculpture with patterns carved on the forehead and cheeks, unearthed at the Shuangdun ruins (Figure 1), as a national first-grade cultural relic, is the most ancient physical proof of carved facial patterns discovered in China so far. Therefore, whether considered from the perspective of cultural relic exploration or started on the discussion of the implicit connotation in the Huaihe River civilization system, it is worthwhile to conduct an ample academic discussion on this cultural relic.
Considering the deficiency of prehistoric documentation, we take the Philosophy of Symbolic Forms proposed by the German philosopher Ernst Cassirer as the theoretical basis, which was not only full of culturally "meaningful forms", but also introduced "images to represent the fundamentals and concepts of a specific culture, that is, symbolic value" and regard the artistic works as the "documentation" of artists, religions, philosophy, and even the entire civilization [2]. From the perspective of art history, analyzed with iconography, the paper dedicates to interpreting the theme conveyed in the visual art of the pottery sculpture and the deep implicit meaning and establishing the connection between the physical proof and the historical background.

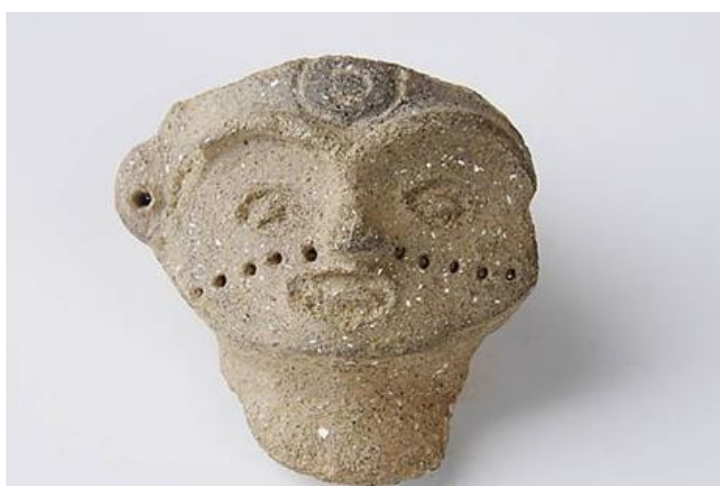

Figure 1: The pottery head sculpture with patterns carved on the forehead and cheeks

\section{Method Selection}

American anthropologist Franz Boas believed that the development of the technique to a certain level leads to a corresponding development of decorative arts. Therefore, the development of the technique and art can be linked up reciprocally. Based on the achievability of technology, the pottery head sculpture with patterns on the forehead and

Volume 8 Issue 6, 2021

www.jissr.net 
cheeks are spiritual products derived from practical products. It is permeated by the spiritual connotation of primitive people and also exhibiting the prominent features of primitive art, such as immature and plain forms, rich and audacious imagination, simple and straightforward spiritual expression, chaos, etc. Therefore, the paper adopts Iconography developed from the analysis method of three stages and Iconology from that of the fourth stages proposed by Erwin Panofsky [3]. There are three stages of Iconography, namely, are pre-iconography description, iconography description, and iconography interpretation that describes and interprets from the dimension of visual art. While iconology interpretation, as the fourth stage, reveals the relationship between visual art and historical background from the dimension of research on cultural history.

\section{Pre-iconography Description}

Since the pottery head sculpture with patterns carved on the forehead and cheeks is an unadorned reproducible art relatively, we directly observe and describe the various components of the work on the premise of excluding the interrelationship in the stage of pre-iconography description.

The measurement shows that the head is $6.3 \mathrm{~cm}$ high and 6.5 $\mathrm{cm}$ wide. Observation shows that the head sculpture includes a neck. Observing from the front, the shape of the neck is visible, its lower part is incomplete, and the back of the head is also damaged, as seen in Part A. The pottery head sculpture was an artifact made from clay mingled with fragments of quartz and mica, which are glowing in the light feebly. There are multiple black remnants on the face of the sculpture. Part $B$ shows the incomplete left ear and the right ear with a perforation. As shown in Part C, the pattern of concentric circles engraved on the forehead is described as "Diaoti" in Chinese. Part D shows the protruding eyebrow arch, the connected eyebrows, the ocular region, and the orbital borders fashioned with poking and pricking. From Part E, we see the pattern of a ring carved on the tip of the nose, and two patterns of strings composed of five circular apertures, spreading out downwards along each cheek from each wing of the nose. The set of patterns is described as "Wenmian" in Chinese. We see a slightly open mouth in Part F, and its contour is crafted by the techniques of poking and pricking, as shown in Part G. From the perspective of a whole, the facial features of the sculpture are appropriately proportioned, and the contrast between protrusions and concavities is moderate, as shown in Part H.

\section{Iconography Description}

In the stage of iconography description, what we need to discuss is the theme of the work of art. As one of the earliest sculptures of human figures in China, the pottery head sculpture with patterns carved on the forehead and cheeks, there are few precedents to compare with it. Reviewing the point of view proposed by Panofsky that from the perspective of art history, art does not have a term of progress, but rather different symbolic forms have been developed in different periods, conveying the similar idea that "art transcends time and space" in Chinese art theory. Within the scope of the period of prehistoric art, by expanding the time span of the reference range forwards and backward, we can locate the resemblances and characteristics between images.

\subsection{Part A}

In this part, we describe the overall specification and format of the work of art. Referring to the pottery head sculpture of the maiden $(12.6 \mathrm{~cm}$ high) unearthed at Yangshao cultural ruins of Yangshao village, Lixian county, Gansu province, and the crimson pottery face sculpture $(15.3 \mathrm{~cm}$ high) from Yangshao cultural ruins of Tianshui City, Gansu province, we carry out the discussion. In appearance, three works of art were all crafted as sculptures with necks; in terms of dimension, it is obvious that the pottery head sculpture with patterns carved on the forehead and cheeks is a small pottery sculpture of $6.5 \mathrm{~cm}$ high, differentiating from the other two pieces to a certain extent; and in terms of completeness, like the other two work of arts, there are missing or damaged parts in their necks. Moreover, it is the characteristic of the complete pottery unearthed at the Shuangdun culture ruins to be polished for symbolic engraving on their flat bottoms. Consequently, it inevitably causes us to associate them with incomplete works of art. Therefore, taking all these characteristics together, we summed up a phrase to describe Part A, that is, the incomplete head sculpture.

\subsection{Part B}

In this part, we describe the texture of the work of art. When discussing the texture of works of art, we trace back to the three cultural periods in the latter span of the early Neolithic Age, namely Peiligang Culture, Cishan Culture, and Laoguantai Culture, and also extend to Ancient Shu Culture of Sanxingdui ruins. Most of the pottery that emerged in the three earlier cultures was mingled with impurities. For the reason that the people mingled pottery clay with quartz grains, sand, mica powder, and shell fragments, etc., and the temperature was not high enough during firing, the pottery products resulted in loose textures. By observing the pottery of the ancient Shu culture unearthed at Sanxingdui ruins, we found that the people of Sanxingdui culture added shell fragments, quartz sand, mica, plant fibers, etc. during the production, and coated the surface of the pottery with the sludge of clay to make it appear glossy and exquisite. The outer layer of the pottery eroded over time, eventually falling off and revealing the rough inner texture.

The majority of the pottery of the Shuangdun culture in the Mesolithic Age were artifacts crafted from the materials of clam-mingled clay and charcoal-mingled clay, and a small amount of mica-mingled clay, in addition, containing a small amount of sand in the pottery fetus. Clam-mingled pottery accounts for about $80 \%$ of the total unearthed, most of which are cookware and the lids of other larger utensils, and the rest are some storage utensils. The sidewalls of this type of pottery are rough and thick, the inner and outer surfaces of the finished products are rough, leaving imprints of scratching or daubing, and assembly marks. Charcoal-mingled pottery accounts for about $17.1 \%$, most of which are bowls, measuring bins, and so on. The sidewalls of this type of pottery are relatively thin. The inner and outer surfaces of the finished products are polished up smoothly, and the outer surfaces are covered up with a red coating. The remaining $2.9 \%$ are a small amount of mica-mingled pottery and a minute quantity of washed-out clay pottery [4]. The aforementioned shows that the Shuangdun culture people then had already been selecting and refining the clay subjectively, and wielding 
technique of washing out the clay, and the mica-mingled pottery was regarded as superior pottery comparatively.

It is observed that there are multiple black remnants on the facial segment of the pottery head sculpture with patterns carved on the forehead and cheeks. So we compared it with other mica-mingled pottery unearthed at the Shuangdun cultural ruins and found that there are black remnants of various sizes on all these mica-mingled pottery, and then associated with the jars of mica-mingled pottery unearthed at the Shuangdun ruins in 1986, of which the black pottery coating was well preserved (Figure 2), it can be inferred that there was pottery clay originally daubed on the outer layer of the pottery head sculpture, but it eventually fell off over time and thereby revealing the inner texture.

So we summed up a phrase to describe Part B, that is, micamingled painted pottery.

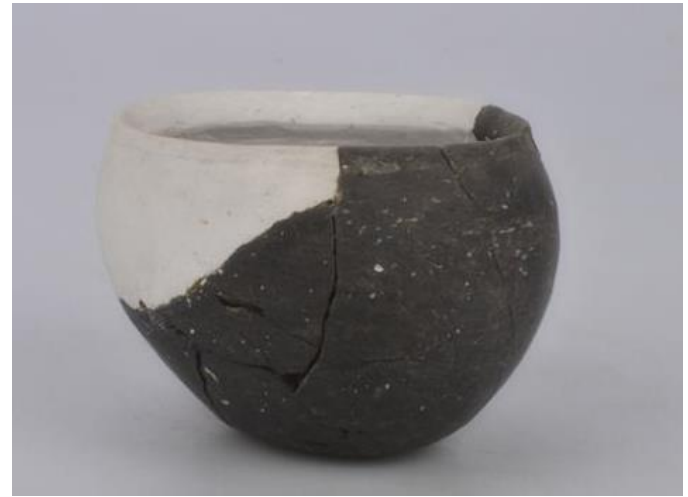

Figure 2: The jars of mica-mingled pottery unearthed at the Shuangdun ruins in 1986

\subsection{Part C}

In this part, we describe the ears of the work of art. We associated with the pottery head sculpture of the maiden unearthed at Yangshao cultural ruins of Yangshao village, Lixian county, Gansu province, and a painted pottery vase with an opening in the shape of a human head at Dadiwan ruins of Qin'an county, Gansu province, and found that there is a common feature among the three pieces of pottery, that is, ear perforation. So Part $\mathrm{C}$ is described as perforated ears.

\subsection{Part D}

In this part, we describe the forehead patterns of the work of art, specifically referring to the engraving of the concentric circles on the forehead of the pottery head sculpture. We associated them with the jade tablet $(87 \mathrm{M} 4: 30)$ of the Lingjiatan ruins and multiple engraved solar symbols unearthed at the Shuangdun culture ruins. In the interpretation of the patterns in the jade tablet (87M4:30) of the Lingjiatan ruins, the majority of the scholars regarded the double concentric circles as the firmament[5], the octagonal star pattern as the sun, or the celestial pole, and the surrounding patterns of grids as Siwei-Bafang. (Siwei refers to the four directions of southeast, southwest, northeast, and northwest; Bafang refers to Siwei and the other four directions in east, south, west, and north). And among the multiple engraved solar symbols unearthed at Shuangdun culture ruins, whether they are patterns engraved on the bottom of the vessels or the combination of patterns engraved on the bottom and lower edge of them were depicted as the shining bright sun. According to the research of archaeological experts, the engraved symbols unearthed at Shuangdun culture ruins were characterized with repeated patterns, which have risen to the stage of conception expression. Therefore, we inferred that rather than interpreting the concentric circle patterns as the sun, it is closer to interpretation as the firmament. So we describe Part $\mathrm{D}$ as the forehead pattern of the firmament.

\subsection{Part E}

In this part, we describe the ocular characteristics of the work of art, referring to the facial pattern pottery shard unearthed at the Shuangdun cultural ruins (Figure 3) and the crimson facial pottery sculpture of the Yangshao cultural ruins in Tianshui city, Gansu province. According to the research on the engraved patterns of pottery shards unearthed at the same cultural ruins, it can be seen that during the Shuangdun culture period, there is a commonality in the aesthetics of portraits. The difference between the two works of art is merely the adjustments based on the different artistic carriers. Comparing the facial patterns to the crimson facial pottery sculpture of the Yangshao cultural ruins, it can be found that both are with protruding eyebrow arches and connected eyebrows. Moreover, both the choices of the shape of the eyes were identical, except that the crafting of the crimson facial pottery sculpture selected the approach of hollowing for use as a mask. So we can describe Part E as circular eyes with protruding eyebrow arches and connected eyebrows.

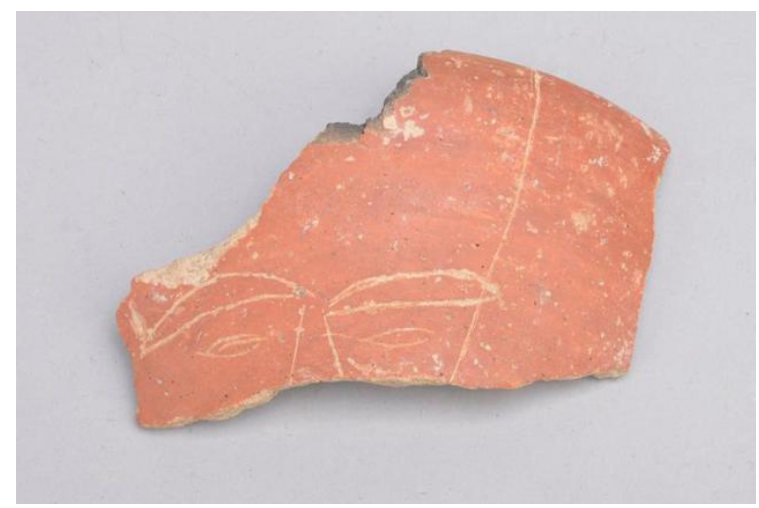

Figure 3: The facial pattern pottery shard unearthed at the Shuangdun cultural ruins

\subsection{Part F}

In this part, we describe the facial center of the work of art, referring to the facial tattoo tradition of the Dulong females. Due to erosion, the circular pattern carved on the nose tip of the pottery head sculpture is not distinct, thus classified as an overlooked icon. Clear nose-tip patterns can be seen on the large-scale theme sculptures in Bengbu city, Anhui province. Comparing the picture of the facial pattern of the head sculpture with the facial tattoos of Dulong female, we found that in the facial tattoos of the Dulong ethnic group, the stripes on the cheeks consist of dots less than half a centimeter apart from each other, and those in the left and right cheek are mainly symmetrical, and there are also patterns on the nose tip [6]. The patterns of both facial centers are visually in the same category. So we describe Part F as a facial pattern composed of dots symmetrically spreading out from the nose tip to both cheeks. 


\subsection{Part G}

In this part, we describe the oral features of the work of art, with reference to the pottery head sculpture of the maiden unearthed at Yangshao culture ruins of Yangshao village, Lixian county, Gansu province, and a carved stone head from the Cishan ruins in Wu'an city, Hebei province. There is a common oral feature among these three artifacts, specifically that they are all slightly opened. However, unlike the hollowing technique of the pottery head sculpture of the maiden, except leaving a hole in the oral area, the mouth of the carved stone head had a contour built up, as well as the pottery head sculpture with patterns carved on the forehead and cheeks. Because of the choice of different materials, the chiseling approach was introduced to craft the mouth of the carved stone head, while the dot-poking approach was introduced for the pottery head sculpture with patterns in the forehead and cheeks. Therefore, we describe Part G as the mouth with a contour dot-poked.

\subsection{Part H}

In this part, we describe the overall style of the work, which can still be associated with the facial pattern pottery shard unearthed at the Shuangdun cultural ruins. It can be seen that Shuangdun people's craft of the five senses organs of the sculpture was still rudimentary, but the creative attitude was well-reflected. The application of carving, molding, dotpoking and other techniques made the creation break through the boundaries of the plane, reflecting the Shuangdun people's understanding of three-dimensional space. Consequently, we describe Part $\mathrm{H}$ as a realistic primitive sculpture.

\section{Iconography Interpretation}

In the stage of iconography interpretation, we collaborate with the descriptions of the two foregoing stages, focusing the discussion on the meaning implied or derived from the creative intentions of the creator of the pottery head sculpture with patterns on the forehead and cheeks.

The prehistoric sculptures were artifacts commonly crafted for practical purposes, such as the implementation of witchcraft, the worship of mother gods, etc., thus reflecting the corresponding features of the pattern externally, rather than visual art representation. The ancient art of primitive society prioritized the social significance over the forms of art, in that case, we regard those patterns observed in the research as accumulated sensibility, that is, a product of form and structure from natural socialization and social naturalization of prehistoric ancestors. Thus, the collective unconsciousness is also worthy of attention accordingly.

The first subject that needs to discuss first is the patterns carved on the forehead and cheeks of the pottery head sculpture. We know that different approaches and cultural backgrounds during observation lead to distinct conclusions. More or less, it got verified in the different descriptions of the facial tattoo portrait of the Maori chief by both the British J. Sylvester and the Maori chief Te Pehi Kupe (Figure 4). We have no way of knowing the perspective of the Shuangdun people at that time. Perhaps people have not looked at the patterns from an overall perspective of three dimensions, but of sculpting a relatively flat mask. Based on the idea, the facial patterns of the pottery head sculpture can be interpreted as the composition of a painting. The concentric circles on the upper part of the canvas represent the sky, and the dot stripes on the lower part represent the earth or repose, reflecting a kind of primitive conception of the world.
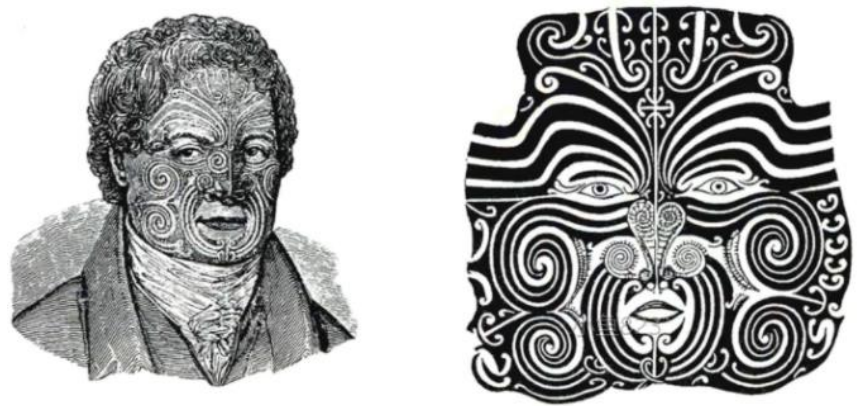

Figure 4: The facial tattoo portrait of the Maori chief by both the British J. Sylvester and the Maori chief Te Pehi Kupe

The next thing that needs discussion is the dots and circles that appear on the sculpture face, as well as the forms of successive dots symmetrical about the nose as the vertical axis. We can perceive that whether used for the crafting of facial contours, carved patterns, or facial features, circles accord with the basic principles of Chinese art and philosophy, such as a circle to represent an ideal state, a circle to imply a new start, to represent a change, and the like. The philosophy embodied in Shuangdun people's works is more likely to be understood as the creation of unconsciousness, artistic images that humans in the primitive age accumulated from nature and entrusted their subjective emotions.

Finally, we discuss the meaning conveyed as a whole by the pottery head sculpture with patterns carved on the forehead and cheeks. The production and manufacturing of the ancients also adhered to the laws of nature. In the previous stage, we described this work of art as the incomplete head sculpture, which means it is an incomplete artifact. The size enhanced its portability. Referred to the jade sculpture of a standing male from the Lingjiatan ruins, which belongs to the same Huaihe culture system, there are perforations in the lower part of its back, we are aware that people in the Huaihe River basin at that time were wearing ornaments. Based on its practical application, thus we speculate that it is a pottery sculpture that is portable and has special significance.

\section{Iconology Interpretation}

Belinsky believed that the secret of the attribute of each nationality lies not in their clothing or cuisine, but in the way they understand things. In the stage of iconology interpretation, we reveal the reasons and purposes of creating specific images in visual art based on a broader cultural background.

Despite the lack of prehistoric documentation, more or less, we still learned from some later documents. For example, it is depicted in King's Courtesy of Classic Etiquette that the barbarians in the east are called $\mathrm{Yi}$, who is disheveled, tattooed, and eating raw food, while the barbarians in the south are called Man, who is tattooed on their foreheads, with apes-like big toes, and eating raw food. 
According to the Atlas of Chinese Historical Manuscripts edited by Guo Moruo, the Dynasties of Xia, Shang, and Western Zhou marked Yi of the Huaihe on the maps of the Huaihe River basin and other spots. Based on the historical records of the Zhou Dynasty, the Zhou Dynasty collectively referred to the Yi people in the middle and lower reaches of the Huaihe River as the $\mathrm{Yi}$ of $\mathrm{Xu}$ or the $\mathrm{Yi}$ of Huaihe. $\mathrm{Wu}$ Hong mentioned in Art in Its Ritual Context that in ancient China, due to flooding and sea encroachment, the coastline went much further into eastern China than it does now, and the Shuangdun cultural location was actually a marshy land near the coast. Concluded from the aforementioned documentation, the middle and lower reaches of the Huaihe River Basin where Shuangdun cultural ruins of Bengbu city locates, belong to the scope of the Yi of Huaihe, which is the East Yi among the Nine Factions of Yi recorded in historical materials.

We have also obtained plenty of information from the materials unearthed at the Shuangdun cultural ruins [7]. For example, judging from the unearthed spinning wheels and engraving silkworm symbols, it is known that the Shuangdun culture people had already mastered the techniques of silkworm raising and silk reeling at that time, while from fishing and hunting instruments, engraving hog symbols, engraving symbols of stilt buildings, and carbonized rice, it can be seen that the Shuangdun culture people were living in the transitional period between the economy of fishinghunting-gathering and rice agriculture economy at that time. From the unearthed pottery genital sculpture of the male, it can be seen that the men of the Shuangdun culture were the main social productive force and the principal creators of social wealth, indicating the earlier arrival of the patrilineal society.

Combining with the above historical background, we found that the elements for the birth of the pottery head sculpture with patterns on the forehead and cheeks had been fully available. Because Shuangdun culture people had achieved progress in pottery craftsmanship, they utilized different materials to craft corresponding utensils according to their needs. Due to the enhancement of the human' s ability to conquer nature, we have the opportunity to see the human figures of pottery sculptures. Just as Freud had said that worship is a derivative of animism. Relying on the productivity at that time, the Shuangdun culture spared the surplus energy to create ornaments, and the early animism got turned to the hero-worship. This conversion, which was denoted in the pottery head sculpture, was represented by emphasizing the portrayal of the five sensory organs in the artifacts. The realistic style in the pottery head sculpture was aiming to emphasize the personification of the deities. It is because of Yi' $\mathrm{s}$ convention of tattooing on the foreheads and cheeks that there are corresponding patterns on the artifacts. And their specific choices of symbols were related to the use of the solar calendar by the Shuangdun culture people at that period and the development of more radical ideology.

\section{Conclusion}

Xie He once said that iconography help to reveal the stories in thousands of years, to allude to the historical significance of paintings. As a matter of fact, this argument also applies to prehistoric works of art. In the era of lack of documentation, we hope to interpret a piece of history with the help of physical proofs. However, in this paper, through the method of the iconography of art history, the work of art that has been accumulated for millenniums was confronted more intuitively. We started with the details to piece together the jigsaw and then connected the cultural and historical backgrounds to accomplish the exploration of the pottery head sculpture with patterns on the forehead and cheeks. And with the accomplishment regarded as a basis, the pottery head sculpture was interpreted as a feature of the Shuangdun culture of the Huaihe River culture system. The sentence by Clive Bell epitomizes its value of artistic beauty, which is, there is no accurate reproduction in primitive art, but meaningful forms. Therefore, the profound touch that primitive art has brought about is unmatched to rival any other art.

\section{References}

[1] Su Binqi, A Brief Discussion on the Neolithic Archaeology in the Southeast Coastal Areas of China, the Cultural Relics, Vol.3, 1987.

[2] Ernst Cassirer, The Philosophy of Symbolic Forms, New Haven, 1953-1996.

[3] Chang Ningsheng, The Method and Application of Iconology in Art History, World Art, Vol.1, 2004.

[4] Kan Xuhang, Zhou Qun, The Excavation of Neolithic Shuangdun ruins in Bengbu City, Anhui Province, Journal of Archaeology, Vol.1, 2007.

[5] Li Xinwei, The Concept of Celestial Pole Reflected in Chinese Prehistoric Pottery Patterns, Central Plains cultural relics, Vol.3, 2020.

[6] Bai Ruiyan, The Research on the Facial Tattoos of Dulong Women, Sichuan University, 2008.

[7] Kan Xuhang, Zhou Qun, The Excavation of Neolithic Shuangdun ruins in Bengbu City, Anhui Province, Journal of Archaeology, Vol.1, 2007.

\section{Author Profile}

Xinyu Dai now studying in the Department of visual communication design, Anhui University of Finance and economics. 